\title{
Old wine in new skins
}

\section{Thoughts on academic library Web guides}

$\mathbf{T}_{\mathrm{s}}^{\mathrm{h}}$

he library Web guide originated in the early days of the Web, a child of the venerable "pathfinder." While the traditional pathfinder guided library patrons to appropriate print resources, the Web guide focused on helping them navigate the new and uncharted waters of the online environment. The Web was different in those days. Quality content was hard to find. Search engines weren't very good. If you were lucky enough to find a good Web site, you needed to bookmark it or you might never find your way back. Not only was the Web different, users were different. We lacked the decade or more of experience that most of us have today.

The early Web guides inherited their basic philosophy from the pathfinder. Both tools began with the assumption that there were a finite number of appropriate resources in a finite collection that may be difficult for a nonspecialist to locate. This same model was applied to the Web guide: a finite number of hard-to-find resources.

Things have changed. To begin with, search engines often work quite well. They work so well, in fact, that it is often faster to search for a known Web site than to type its URL into the address bar or look for a link on a known page. This technique works well even for unsophisticated queries. Library patrons do not need our help to find CNN, or even the White House (the hoary old "information literacy" example notwithstanding). ${ }^{1}$

The fundamental problem of navigating the Web has changed. It is no longer a matter of trying to find something useful, but rather of finding the most useful items in an ocean of sites. Comprehensiveness is neither possible nor desirable.

Has the day of the library Web guide passed, or is there a way that these research tools can be re-envisioned for the modern Web? I would argue that librarians still have an important role to play in directing users to useful sites, but we need to approach our Web guides in a more thoughtful and selective manner. Below I propose some guidelines for a successful 21st-century Web guide.

\section{Have a target audience}

For whom are you composing the guide? Is it primarily aimed at undergraduates, graduate students, or faculty members? This will affect not only the sources that you choose, but how you organize those sources and the language you use to describe them. A section of a guide on "bibliographic databases" might be useful for faculty members, but you might want to call it "find articles" if your guide is created for undergrads.

\section{Have a purpose}

Once you have defined your target audience, define the service you want to provide for them. Will the page serve as a general starting point for research or is it designed to answer particular types of questions? Is the page intended for a particular class or assignment? At this stage it may be useful to think about what your guide can do that a list of Google results cannot.

Ron Gilmour is science librarian at Ithaca College, e-mail: rgilmour@ithaca.edu

(c) 2010 Ron Gilmour 


\section{Have a collection development policy}

This may only exist in your mind, but it needs to exist. It should flow naturally from your guide's purpose. Do not include a site just because it "has to do with" your topic. Ask yourself if it fulfills your purpose for your audience. It is common to see professional organizations listed on Web guides, yet these pages often provide little information beyond upcoming conference dates and publication guidelines for the organization's journal. This information is of little value to an undergraduate student. One benefit to having a policy is that it will prevent your guide from growing out of control (see "Keep it short," below).

One general rule that I observe: I rarely link to "meta-sites" (i.e., sites whose primary purpose is to link to other sites). Due to the historical factors mentioned above, a large portion of the Web is devoted to linking to other parts of the Web. You are already constructing one list. Linking to other lists can lead patrons down a frustrating road of endless links and little content.

\section{Select the appropriate level of link specificity}

Is it really useful to link to the homepage of the U.S. Geological Survey? What do you envision a patron doing once he arrives there? Some Web sites, including those of many government agencies, are so vast that just providing a link to the main site is almost useless. At the very least, you should provide some tips on how the visitor should proceed. Better yet, link directly to pages of interest (e.g., "earthquakes"). The specific page will almost certainly feature a direct link "up" to the main site, if the visitor wishes to explore further, but the path "down" from the homepage to the content of interest may be hard to find.

\section{Decide on an organizational scheme}

This is where you get to exercise one of the traditional strengths of our profession. Generally, we're pretty good at organizing stuff. Sadly, we often organize things in ways that make sense only to ourselves. An example is the Web guide that is organized by resource type, as if patrons come to the library thinking, "I'd like to see a handbook about organic chemistry." Patrons have questions to which they want answers. It is our job to know the types of resources and when they are appropriate, not theirs.

A related issue is whether to highlight print resources in a Web guide. I favor this practice, based on the philosophy expressed above that our patrons want information regardless of where it may be found. It could be argued that for certain user groups (e.g., undergraduates) this may not be the case, and that for those groups Web resources may be perceived as inherently more valuable than those in print. Inclusion of print resources can be seen as a marketing strategy. We spend a great deal of money on books. Web guides are an easy way to promote their use.

Here are a few organizational schemes that you might consider:

\section{Functional}

Don't ask what the source is, but what it does. What type of questions does the source answer? For example, you might group resources that provide statistical information about the topic together, or those that offer simple introductory material.

\section{Subject}

This is an obvious organizational scheme for subject areas that are traditionally broken down into fairly discrete categories (e.g., organic vs. inorganic chemistry, micro- vs. macroeconomics). Such organizational schemes have the advantage of following the way that practitioners think about their discipline rather than the way librarians think about it.

\section{Geographic scope}

For many subject areas, especially where government information is significant, it may

(continues on page 357) 
things have been done in the past is not working. With this information, librarians can use their connections on campus, in the greater educational community, and in the policy world. We can lead initiatives that will make use of existing research and propose further studies that identify practical interventions that will develop information literacy competency. We can influence scientists and vendors to develop technology solutions that better synthesize, filter, and organize the volume of information available. We can create new organizational models for our libraries that make best use of our resources to more effectively accomplish the information literacy agenda. We can partner with faculty, graduate students, and others who have teaching roles to coach them on teaching information literacy competencies.

Let's use this study to motivate new, nontraditional ways of thinking about the problem. Continuing to address information literacy issues of this magnitude in the same ways is not going to change the result.

\section{Note}

1. "Lessons Learned: How College Students Seek Information in the Digital Age" can be viewed at http://projectinfolit.org/pdfs /PIL_Fall2009_Year1Report_12_2009.pdf. $\boldsymbol{n}$

("Old wine in new skins," continued from page 351)

be useful to group items as international, federal, state, etc.

\section{Annotate}

Annotations needn't be extensive. In fact, if they are, they are unlikely to be read. Write your annotations to answer the question, "Why would I want to visit this site?" You might also note the sponsorship or authorship of the Web site if this is not obvious from its title, as well as any limitations or restrictions on the site (e.g., "requires registration"),

\section{Keep it short}

Long, multiscreen lists are not attractive. Trained by Google, users will focus on the first few links and give decreasing attention to those farther down the page.

Remember to weed your guide. Just as in the stacks, some materials become outdated and new materials become available. If you only add to your guide without subtracting, you will soon have a sprawling mess. As you review your guides, ask not only "Is this still relevant?" but also "Is this still the best?"

\section{If you can't keep it short, make it modular} If you find that despite strict adherence to your collection development policy and vigilant weeding, your guide still sprawls, your next option is to split up the guide into multiple pages. By splitting your guide into more narrowly targeted units, you make it easier to navigate and more attractive to patrons.

\section{Keep a consistent look and feel}

Ideally, authors of subject guides should be free from the burden of page design. While a basic knowledge of HTML is increasingly common among librarians, there is no reason for every subject specialist to be a Web author. There are specialized content management systems available, notably SubjectsPlus (open source) and LibGuides (commercial), which will allow librarians to construct subject guides by simply adding resources and annotations to a database. This approach offers a number of benefits: it separates the tasks of content authorship and design, it facilitates updating of sources by letting multiple guides point to a single entry in the database, and it ensures consistency among all of a library's Web guides.

\section{But make it unique}

The dark side to consistency is boredom. If your system allows, it's a good idea to add something so that your guide doesn't look

(continues on page 373) 